\title{
Translocation of an arctic seashore plant reveals signs of maladaptation to altered climatic conditions
}

\author{
Maria Hällfors ${ }^{\text {Corresp., } 1,2}$, Susanna Lehvävirta ${ }^{2,3}$, Tone Aandahl ${ }^{4}$, Iida-Maria Lehtimäki ${ }^{2}$, Lars Ola Nilsson ${ }^{4,5}$, Anna \\ Ruotsalainen $^{6}$, Leif E Schulman ${ }^{2}$, Marko T Hyvärinen ${ }^{2}$ \\ ${ }^{1}$ Research Centre for Environmental Change, Organismal and Evolutionary Biology Research Programme, Faculty of Biological and Environmental \\ Sciences, University of Helsinki, Helsinki, Finland \\ 2 University of Helsinki, Botany Unit, Finnish Museum of Natural History, Helsinki, Finland \\ 3 Swedish University of Agricultural Sciences, Department of Landscape Architecture, Planning and Management, Alnarp, Sweden \\ 4 Norwegian Institute of Bioeconomy Research (NIBIO), Division of Environment and Natural Resources, Ås, Norway \\ 5 Halmstad University, Halmstad, Sweden \\ 6 University of Oulu, Department of Ecology and Genetics, Oulu, Finland \\ Corresponding Author: Maria Hällfors \\ Email address: maria.hallfors@helsinki.fi
}

Ongoing anthropogenic climate change alters the local climatic conditions to which species may be adapted. Information on species' climatic requirements and their intraspecific variation is necessary for predicting the effects of climate change on biodiversity. We used a climatic gradient to test whether populations of two allopatric varieties of an arctic seashore herb (Primula nutans ssp. finmarchica) show adaptation to their local climates and how a future warmer climate may affect them. Our experimental set-up combined a reciprocal translocation within the distribution range of the species with an experiment testing the performance of the sampled populations in warmer climatic conditions south of their range. We monitored survival, size, and flowering over four growing seasons as measures of performance and, thus, proxies of fitness. We found that both varieties performed better in experimental gardens towards the north. Interestingly, highest up in the north, the southern variety outperformed the northern one. Supported by weather data, this suggests that the climatic optima of both varieties have moved at least partly outside their current range. Further warming would make the current environments of both varieties even less suitable. We conclude that Primula nutans ssp. finmarchica is already suffering from adaptational lag due to climate change, and that further warming may increase this maladaptation, especially for the northern variety. The study also highlights that it is not sufficient to run only reciprocal translocation experiments. Climate change is already shifting the optimum conditions for many species and adaptation needs also to be tested outside the current range of the focal taxon in order to include both historic conditions and future conditions. 
1 Translocation of an arctic seashore plant reveals signs of maladaptation to altered climatic

2 conditions

3

4 Hällfors M.H. ${ }^{* a, b}$, Lehvävirta S. ${ }^{\text {a,c }}$, Aandahl T.R. ${ }^{\text {, }}$, Lehtimäki I.-M. ${ }^{\text {, }}$, Nilsson L.O. d,e,

5 Ruotsalainen A.L. ${ }^{f}$, Schulman L.E. ${ }^{a}$, Hyvärinen M.-T. ${ }^{a}$

7 a Botany Unit, Finnish Museum of Natural History, P.O. Box 7, FI-00014 University of Helsinki, 8 Finland.

$9 \quad{ }^{b}$ Research Centre for Environmental Change, Organismal and Evolutionary Biology Research

10 Programme, Faculty of Biological and Environmental Sciences, P.O. Box 65, FI-00014

11 University of Helsinki, Finland.

$12{ }^{\mathrm{c}}$ Department of Landscape Architecture, Planning and Management, Swedish University of

13 Agricultural Sciences, Alnarp, Sweden

$14{ }^{\mathrm{d}}$ Division of Environment and Natural Resources, Norwegian Institute of Bioeconomy Research

15 (NIBIO), P.O. Box 115, NO-1431 Ås, Norway.

16 e Halmstad University, PO Box 823, SE-30118 Halmstad, Sweden.

$17 \mathrm{f}$ Department of Ecology and Genetics, P.O. Box 3000, FI-90014 University of Oulu, Finland.

19 * corresponding author. Contact information: Maria Hällfors, Research Centre for Environmental 20 Change, Organismal and Evolutionary Biology Research Programme, Faculty of Biological and 21 Environmental Sciences, P.O. Box 65, FI-00014 University of Helsinki, Finland, e-mail:

22 maria.hallfors@helsinki.fi; phone: +358 407213474 


\section{Abstract}

26 Ongoing anthropogenic climate change alters the local climatic conditions to which species may

27 be adapted. Information on species' climatic requirements and their intraspecific variation is 28 necessary for predicting the effects of climate change on biodiversity. We used a climatic 29 gradient to test whether populations of two allopatric varieties of an arctic seashore herb 30 (Primula nutans ssp. finmarchica) show adaptation to their local climates and how a future 31 warmer climate may affect them. Our experimental set-up combined a reciprocal translocation 32 within the distribution range of the species with an experiment testing the performance of the sampled populations in warmer climatic conditions south of their range. We monitored survival,

34 size, and flowering over four growing seasons as measures of performance and, thus, proxies of 35 fitness. We found that both varieties performed better in experimental gardens towards the north. 36 Interestingly, highest up in the north, the southern variety outperformed the northern one.

37 Supported by weather data, this suggests that the climatic optima of both varieties have moved at 38 least partly outside their current range. Further warming would make the current environments of 39 both varieties even less suitable. We conclude that Primula nutans ssp. finmarchica is already suffering from adaptational lag due to climate change, and that further warming may increase

41 this maladaptation, especially for the northern variety. The study also highlights that it is not 42 sufficient to run only reciprocal translocation experiments. Climate change is already shifting the 43 optimum conditions for many species and adaptation needs also to be tested outside the current 44 range of the focal taxon in order to include both historic conditions and future conditions. 


\section{Introduction}

48 Ongoing climate change threatens biodiversity and is predicted, and even shown, to lead to

49 declines in populations and to extinctions of species (Ceballos et al., 2015; Dawson et al., 2011;

50 Díaz et al., 2019; Settele et al., 2014; Urban, 2015). The ability of species to respond, in situ, to

51 shifting environmental conditions can be a result of tolerance of a broad range of conditions, or it

52 can be mediated through evolutionary adaptation (Chevin et al., 2010; Gao et al., 2018; Gienapp

53 et al., 2008; Merilä \& Hendry, 2014) sometimes facilitated by gene flow from congeneric

54 populations. In order to enable assessment of the ability of a species or population to cope with

55 increasing pressures, it is crucial to understand through which mechanisms the impact of climate

56 change is manifested.

57

58 Phenotypic plasticity can allow organisms to respond rapidly to changes in their environment

59 and, hence, it has often been viewed as the main strategy to respond to environmental changes

60 (Merilä, 2012). In contrast, evolutionary processes are often slow. Some species are showing

61 signs of acclimatization or adaptation to new conditions, whereas others are either declining or

62 dispersing to new areas with a favourable environment (Lenoir \& Svenning, 2015; Parmesan \&

63 Yohe, 2003; Pöyry et al., 2009). To predict the effects of climate change on biodiversity and to

64 plan effective conservation strategies, we need both evaluations of how the current distribution

65 areas of species are changing, and approximations of the genetic and phenotypic potential of

66 species to endure climatic changes in situ.

67

68 Species are often used as the basic taxonomic unit in plant conservation, and predictions on the

69 effects of environmental change usually relate to the species level (Frankham et al., 2012). 
70 Populations of a particular species may, however, be locally adapted, and therefore have

71 divergent affinities to abiotic conditions (Banta et al., 2012) and show intraspecific differences in

72 climatic tolerance (Atkins \& Travis, 2010; Hill et al., 2011). However, in their review on local

73 adaptation in plant species, Leimu and Fischer (2008) found that local adaptation of populations

74 to environmental conditions is not as widespread as often assumed. Local adaptation may be

75 favoured mostly in cases where populations occur in differing environments and gene flow

76 between them is restricted (Kawecki \& Ebert, 2004). Understanding and taking into account

77 intraspecific variation in the adaptation to climatic conditions, is necessary to reach balanced

78 estimates of climate change impact at the level of populations (Hällfors et al., 2016; Souther and

79 McGraw 2011; Valladares et al., 2014). The speed of climate change may outpace the ability of

80 populations to respond adaptively, thereby causing adaptational lag (McGraw et al. 2015) and,

81 hence, maladaptation instead of adaptation or acclimatization. Thus, the need to estimate the

82 effect that climate change has had on natural populations to date, has become increasingly

83 evident (Anderson \& Wadgymar, 2020; Franks et al., 2007; Kooyers et al., 2019; McGraw et al.

84 2015; Thomann et al., 2015; Wilczek et al., 2014; Zenni et al., 2014).

85

86 Manipulative experiments have the potential to provide information on how strong a role climate

87 plays in defining favourable conditions of a species or population (Hargreaves et al., 2014;

88 Kawecki \& Ebert, 2004; Kreyling et al., 2014; Pelini et al., 2012). Results from experiments

89 where the climatic conditions for the focal taxa are altered can be incorporated into species

90 distribution models to improve predictions (Greiser et al., 2020). By reciprocally transplanting

91 individuals of two or more populations to conditions representing a foreign environment and a

92 home environment, we can effectively measure intraspecific variation that allows maintenance of 
93 fitness under varying temperature conditions (Blanquart et al., 2013; Kawecki \& Ebert, 2004).

94 Experiments can also test species' responses to future conditions, for example, through

95 treatments mimicking increased temperatures, and inform us about the extent to which plasticity

96 contributes towards population resilience under climate change. Furthermore, such experiments

97 can reveal locally adaptive traits, which would signify that the survival of the species in the

98 future would require either rapid microevolution in situ, a range shift or, in the absence of these,

99 assisted migration (sensu Hällfors et al., 2014) to new favourable areas.

100

101 Here, we describe a study on Siberian primrose (Primula nutans ssp. finmarchica (Jacq.) Á.

102 Löve \& D.), in which we sampled populations of two of its varieties (the northern var.

103 finmarchica and the southern var. jokelae L. Mäkinen \& Y. Mäkinen); while acknowledging that 104 our sampling did not cover the varieties' full distribution, for clarity we refer to the populations 105 of the different varieties by 'variety'. We performed 1) a reciprocal transplant experiment and 2) 106 an experiment of out-of-range transplantation. The former tests the importance of intraspecific 107 local adaptation versus insensitivity towards climatic conditions (Fig. 1 (b) versus (c)), (Fig. 1 (c) 108 versus (d)) and the latter the varieties' capability to survive in future climate conditions. We 109 conducted the experiment across four growing seasons using a network of botanic gardens in 110 Finland, Norway, and Estonia (Fig. 1). Two of the experimental gardens represent the home 111 environments of each variety, forming the reciprocal component in the experiment (Oulu and

112 Svanvik; Fig. 1). Gardens outside of the range of the species (Tartu, Helsinki, Rauma; Fig. 1)

113 were included to simulate the potential future climates. We tested the effect of the variety and the 114 environmental conditions (garden or annual temperature) and their interaction on the 115 performance of plant individuals. 
117 Specifically, we hypothesised that

118 i) The varieties are adapted to local climatic conditions and thus perform better in their 119 home environments (Fig. 1 (b)).

120 ii) Both varieties perform less well in the out-of-range environments, but the southern variety would have higher performance than the northern one in locations with higher temperatures outside the species' natural range (Fig. 1 (b)).

Equally high performance of both varieties in the test environments (Fig. 1 (c)) would reveal a lack of local adaptation, while no affinity towards conditions within the species range should result in an equally high performance of the species within and outside of its range (Fig. 1 (d)). However, because climate change has already proceeded (IPCC, 2019), the process of adaptation may be lagging behind and populations may in fact be maladapted to current climatic condition (Anderson \& Wadgymar, 2020; Kooyers et al., 2019; Wilczek et al., 2014). This scenario of climate change induced maladaptation (Fig. 1 (e)) needs to be taken into account in contemporary translocation studies. Our study set-up thus allowed us to disentangle climatic affinity and infer the occurred and predicted effects of global warming on these two populations of the Siberian primrose.

\section{Materials and Methods}

\section{Study species and seed sampling}

136 Siberian primrose (Primula nutans) is a small-statured perennial herb with a discontinuous,

137 circumpolar distribution. The Fennoscandian subspecies $P$. nutans ssp. finmarchica (Jacq.) Á.

138 Löve \& D. Löve is a red-listed species (VU in Norway and NT in Finland with a disjunct 
139 distribution (Fig. 1). It comprises two morpho-ecological varieties (Mäkinen \& Mäkinen, 1964):

140 var. finmarchica (the northern variety) grows on the shores of the Arctic Sea, while var. jokelae

141 (the southern variety) occurs by the Bothnian Bay and the White Sea (Fig. 1 (a)). It is a habitat

142 specialist that mainly grows in seashore and riverside meadows (Kreivi, Aspi, \& Leskinen, 2011;

143 Mäkinen \& Mäkinen, 1964). The habitat preference of the Siberian primrose is believed not to be

144 affected by specific habitat requirements - it is neither a halophyte nor does it require regular

145 flooding (Mäkinen \& Mäkinen 1964). Rather, its occurrence in these habitats is likely due to its

146 poor ability to compete in combination with a tolerance to both salty conditions and flooding. It

147 propagates sexually by seeds and vegetatively by stolons growing from the wintering buds and

148 the rosettes (Mäkinen \& Mäkinen, 1964). On the basis of matrix models published by

149 Björnström et al. (2011) individuals especially sterile rosettes can be relatively persistent and

150 hence live for several years. The species is insect-pollinated and produces copious seeds that

151 spread by gravitation, via water flows, and possibly also with birds (Ulvinen 1997).

152

153 Due to the geographic distance (c. 400-550 km) between its two varieties var. jokelae and var.

154 finmarchica, and the lack of obvious adaptations for efficient gene flow between the areas, the

155 varieties are presumably genetically isolated, which is also reflected in their genetic differences

156 (Kreivi et al., 2011). The main areas where the varieties occur are climatically different (Hällfors

157 et al., 2016; also see Fig. 2 (a)), and there is a clear difference in the requirement of colder night

158 conditions for flower induction in the northern variety compared to southern variety (Mäkinen \&

159 Mäkinen, 1964).

160

161 We sampled seeds from wild populations of both varieties of Primula nutans ssp. finmarchica 
162 from August to September 2012 (Fig. 1 (a), Table S1). Seeds of the southern variety were

163 collected in five sites in Haukipudas and Ii in Finland, and seeds of the northern variety from six

164 sites in Sør-Varanger in Norway. Seed sampling in Finland was approved by the Centre for

165 Economic Development, Transport and the Environment in North Ostrobothnia, Finland, on July

166 7th, 2012 (approval number: POPELY/346/07.01/2012). For sampling seeds in Norway, no

167 permit was needed as the species is not protected in Norway. Voucher specimens from each

168 sampling site are deposited at the herbarium of the Finnish Museum of Natural History (H sensu

169 Thiers 2016). From each site we collected seeds from 10 - 53 individuals (as available, following

170 seed collecting guidelines; ENSCONET, 2009; Table S1) to obtain a representative sample. The

171 number of seeds obtained from the collected capsules of each sampled individual varied from 0

172 to $c$. 200. We stored the seed lot from each maternal individual separately and left them to dry

173 and ripen at room temperature for a minimum of two weeks after which we placed them in a

174 freezer $\left(-18\right.$ to $\left.-20^{\circ} \mathrm{C}\right)$ for cold stratification to break dormancy. The seeds were kept in these

175 conditions for about six months, until used to produce plant material for the translocation

176 experiment (in spring 2013).

177

178 Experimental design and plant material

179 We set up a common garden experiment in 2013 in five botanic gardens located in Estonia and 180 Finland, and on research station grounds in Norway (Fig. 1 (a); Table S2). We chose to use

181 botanic gardens as testing grounds instead of natural sites to avoid genetic contamination of

182 natural populations by introducing alien genotypes, as well as for logistical reasons and legal

183 restrictions of introducing species outside their natural range. 
185 We chose the seeds for producing experimental plants for the trial through a hierarchical 186 randomized method (Table S1; Fig S1). For each experimental garden, we selected material from 187 three seed sampling sites per variety. From each site, we randomly chose five maternal 188 individuals. We anticipated that not all seeds would germinate and therefore we sowed eight 189 seeds per maternal individual (120 seeds per variety for each site) although we needed only three 190 seedlings per maternal individual (45 seedlings per variety for each site).

191

192 We used the F1 offspring for our tests for two main reasons. Producing a 'refresher' generation 193 between collecting the seeds and growing the experimental plants would have been difficult or 194 impossible in uniform conditions as the two varieties flower in different temperatures conditions 195 (Mäkinen \& Mäkinen 1964). Second, even in the best case, this would have delayed the 196 experiment by at least one, possibly 2-3 years, due to the life history of the focal species.

197 Nevertheless, a recent meta-analysis (Yin et al. 2019) concluded that perennial plants show 198 hardly any transgenerational responses (i.e., effects on the offspring of the ancestor environmental conditions), whereby it is not likely that the use of F1 offspring significantly 200 affected our results.

202 We sowed each seed in a $6 \times 6 \mathrm{~cm}$ pot with commercial sowing soil (Kekkilä) mixed with sand, 203 vermiculite and perlite (5:2:2:0.5 litres, respectively), and with a thin layer of sand on top. The 204 seeds were sown in six cohorts, five weeks before intended planting at each experimental garden 205 (Table S2). They were left to germinate in a greenhouse in Kumpula Botanic Garden in Helsinki, 206 first in a small greenhouse inside the actual greenhouse to enable suitable temperatures during 207 early spring. Temperature conditions varied between 18 and $24^{\circ} \mathrm{C}$ and lighting was set to $12 \mathrm{~h}$ of 
208 extra light $(400 \mathrm{~W})$ during daytime, in addition to the day light reaching the plants through the 209 greenhouse walls.

210

211 Due to poor germination and growth, possibly caused by supraoptimal temperature or a lack of 212 nutrients or light, the seedlings were moved out of the small greenhouse into the actual one to 213 allow cooler temperatures and more light $\left(10-18{ }^{\circ} \mathrm{C}\right.$; Table S2). The moving followed the same 214 order and time intervals as the sowing so that each cohort spent the same amount of time in the 215 small greenhouse. Five days after the move, the pots were given a one-time nutrient addition 216 with a general commercial fertilizer (Kekkilä Taimi-Superex). This is a common procedure 217 when using nutrient poor germination soil. Without fertilization of the soil after seed germination 218 the growth usually comes to a halt.

219

220 For each experimental garden we selected 45 seedlings of each variety, so that each variety was 221 represented by three seed sampling sites, each of which contributed five seedlings from three 222 different maternal individuals (Fig S1). If there were not enough seedlings from a certain 223 maternal individual, we complemented the design with seedlings from another maternal 224 individual of the same seed sampling population (in 69 cases). If there was no other such 225 maternal individual, we used seedlings from another maternal individual from another seed 226 sampling population but of the same variety (in 21 cases).

227

228 Because of a delayed spring in 2013, establishing the experimental plots had to be postponed by 229 three weeks to avoid frozen soil and frost that could kill the seedlings after planting. The 230 approximately two-month-old seedlings were transported and planted during May-June 2013 
231 (see Table S2 for exact dates), starting from the southernmost garden in mid-May (Tartu,

232 Estonia) and reaching north (Svanvik, Norway; Table S2) in late June. The intention was to

233 follow the advance of the season so as to plant as early as possible while avoiding frost damage.

234 In each experimental garden, we planted the seedlings in three $165 \times 145 \times 20 \mathrm{~cm}$ experimental

235 plots with a minimum distance of $30 \mathrm{~m}$ between the plots, following a randomized block design.

236 A filter cloth was placed at the bottom to prevent the ground soil from affecting the growing 237 conditions and to help retain moisture. The plots were filled with fine sand and peat mixture (75 238 and 25 volume- $\%$, respectively) with some added dolomite lime. The intention was to roughly

239 mimic the seashore meadow soils where the species grows in the wild while using commercially 240 available soils that could be obtained in large quantities by a commercial soil provider and 241 transferred to the all experimental gardens. The aim with using the same substrate was to 242 homogenise (to certain extent) the growth conditions and thus to be able to separate the thermal 243 effect from other effects.

245 In each plot, we planted 30 seedlings (i.e., 90 seedlings per garden) in a grid, c. $21 \mathrm{~cm}$ from each 246 other and $30 \mathrm{~cm}$ from the wooden frame. In each plot, 15 seedlings were of the southern and 15 247 of the northern variety, placed in a random order. We placed light metal cages on top of each plot 248 to prevent large animals from interfering with the experiment. Plots were irrigated with c. 20 249 litres of water once a week during the growing season to keep the soil sufficiently moist. 250 Although precipitation is part of climate, the effects of which we attempt to measure, we 251 considered basic watering of the trials necessary as this is a sea-shore plant naturally exposed to 252 high water tables. This watering regime was not intended to directly resemble the seashore 253 meadows in nature, where the water level can vary substantially and occasionally even flood the 
254 plants. Instead, we applied irrigation to avoid large effects of drought, which this seashore 255 species growing on occasionally inundated meadows, would not endure. Thus, watering was 256 done only to the amount to compensate for the fact that our test sites were not at the shoreline, 257 i.e. to mimic the natural sites of the primrose up to a certain baseline so that the plants would not 258 die because of an unnatural unfavourable moisture regime. Plots were also weeded when deemed 259 necessary to avoid effects of competition from other species, as our focus was not on the effect 260 of competition on plant performance.

261

262 Since almost $50 \%$ of the plants died during the first summer (139 individuals of the northern 263 variety and 57 of the southern; likely due to small seedling size and too little irrigation), in the 264 autumn of 2013, the experimental plots were supplemented with left-over plants that had been 265 growing outdoors in Kumpula botanic garden in Helsinki during the summer (dates presented in 266 Table S2). We chose new plants repeating the plant selection process described above for situation 267 where there were not enough representatives of the preselected maternal individual for the 268 experimental garden. We recorded the planting time, to enable differentiating between original and 269 new plants in subsequent analyses. Altogether, 614 individuals were planted in the five gardens 270 during the early and late summer visits.

271

272 To describe the performance of individuals, we measured their survival, size, and flowering 273 (whether they flowered, how many flowers they produced, and when) from year 2014 to 2016. 274 The fitness of genotypes can be described as the relative success with which they transmit their 275 genes to the next generation (Silvertown \& Charlesworth, 2001). Because of the limited temporal 276 extent of our study and because we do not measure the individual's fitness through its ability to 
277 produce viable progeny, we focus on key plant performance measures likely to correlate with

278 fitness. Survival is a definite measure of fitness as a dead individual cannot transmit genes, but

279 survival can also be stochastic. Also, the physical size of an individual and reproductive output, 280 such as abundance of flowering, tend to correlate with plant fitness (Silvertown \& Charlesworth, 281 2001). Each spring $(2014,2015$, and 2016) we recorded flowering presence and abundance.

282 Flowering was inventoried approximately every second day for 14 days after the first flower 283 appeared in that garden in the specific year. In the autumn of the same years, we recorded 284 survival and photographed each surviving plant from above. We assessed plant size from 285 photographs, through digitally cutting out and measuring the area $\left(\mathrm{cm}^{2}\right)$ of the visible vegetative 286 parts. We used the size at the time of planting as a measurement of original size, but 24 287 individuals lack data on that due to missing photographs or insufficient resolution. These 288 individuals were therefore not included in the analyses, and our total $\mathrm{N}$ is reduced from 614 to 289590.

290

291 Weather and climatic data

292 For describing the climatic conditions at the seed sampling sites and experimental gardens, we 293 obtained data on historic climatic conditions (1970-2000; 10 min resolution) and future 294 projections (CMIP5 for 2050, 10 minutes resolution, HADGEM2-ES model) through the 295 Worldclim database (Fick \& Hijmans, 2017). These climatic data were downloaded in R using 296 the getData function in the raster package (Hijmans, 2019). Additionally, we modelled plant 297 performance as a function of mean annual temperature in the experimental gardens during 20132982016 (see below; Fig 2). The weather data were obtained from the Gridded Agro-Meteorological 299 Data in Europe (Joint Research Centre, 2014), which contains meteorological parameters from 
300 European weather stations interpolated on a $25 \times 25 \mathrm{~km}$ grid. We used the function biovar in the

301 package dismo (Hijmans et al., 2017) to calculate bioclimatic variables of the weather data in R.

302

303 We present historic and predicted mean annual temperature for the seed sampling sites and

304 experimental gardens and as a mean across experimental years for each garden in Fig. 2. Mean

305 annual temperature is also shown explicitly for each year in each site in Fig. S4 and S5 together

306 with several additional bioclimatic variables, including annual precipitation sum and mean

307 temperature during the warmest quarter of the year. The current climatic conditions in Tartu,

308 Helsinki, and Rauma roughly correspond to the anticipated future climatic conditions in Oulu

309 and in the distribution area of the southern variety (Fig. 2, Fig. S4). The historic conditions in

310 Oulu roughly correspond to the future conditions in Svanvik and in the distribution area of the

311 northern variety (Fig. 2, Fig. S4)).

312

313 In addition to modelling plant performance as a function of experimental garden and other

314 variables, we conducted an alternative model using weather data instead of experimental garden.

315 To represent weather, we chose annual mean temperature at the experimental gardens across

316 experimental years. Climate parameters tend to be multicollinear, and we do not know which

317 specific aspects of temperature these plants respond to. Thus, mean annual temperature is used as

318 a large-scale descriptor of differences between experimental gardens.

319

320 Statistical analyses

321 To test the performance of the two varieties in the different gardens we analysed their combined

322 performance using aster models (Geyer, Wagenius, \& Shaw, 2007; Shaw et al., 2008). These 
323 models allow the joint analysis of several life history components that together quantify

324 differences in performance, such as survival, flowering and flowering abundance. The complete

325 model (Fig. S2) included plant survival and flowering in each year (0 or 1; Bernoulli error

326 distribution) plus flowering abundance (zero-truncated Poisson distribution of error) that were

327 conditional on survival in the previous year. Whether a plant flowered or not was also

328 conditional on it having survived in the year of flowering. The abundance of flowers per

329 individual was further conditional on that the individual flowered that year.

330

331 These combined responses were modelled using the aster call in the aster package (Geyer et al.,

332 2007; Geyer, 2017) in two main models: one testing the effect of Garden, and one testing the

333 effect of Temperature (mean annual temperature over 2013-2016). Specifically, the responses

334 were modelled as a function of original size at planting (continuous, square-root transformed and

335 thereafter centred around the mean of each variety; see Fig. S3 for distribution of original size

336 per variety and experimental garden), Variety (categorical: Southern and Northern) and either

337 Garden (categorical, 5 levels) or Temperature (continuous) and the interaction between Variety

338 and either Garden or Temperature. To rule out the effect of planting time (early or late summer)

339 we also ran a model including this variable, which did not improve model fit (change in deviance

3401.96 , change in $\mathrm{df}=1, \mathrm{p}=0.16$ ). The estimated mean value parameters represent overall flowering

341 output, that is, the expected flower count during the whole experiment for plants of average

342 original size (Geyer, 2019). We estimate these for each variety at each experimental garden and

343 hereafter refer to these predicted values as the overall performance.

344

345 As we assumed random variation between the three Plots in each garden and between the five to 
346 six Seed sampling sites of each variety, we also fitted random-effect aster models for both main

347 fixed effects (i.e. for the Garden and Temperature model) using the reaster function in the aster

348 package (Geyer, 2017). Predicting plant performance based on random effects models is not

349 straightforward nor directly possible within the aster models package (Geyer et al., 2019; Geyer,

350 Ridley, Latta, Etterson, \& Shaw, 2013; although see Geyer, Ridley, Latta, Etterson, \& Shaw,

351 2010). Nevertheless, as the estimates for the fixed effects were very similar for both the aster

352 models including only fixed effects and the models also including random effects (see Table S4

353 for the Garden-models and Table S5 for the Temperature-models) we obtained predicted values

354 of plant performance based on the fixed effects models using the predict function in the aster

355 package (Tables S6 and S7). Finally, for assessing statistical significance of fixed effects, we

356 conducted likelihood ratio tests (anova) of the full random effects model versus models

357 excluding individual variables (Table 1). To interpret the role of mean annual temperature for

358 explaining differences in performance between the varieties, we additionally calculated

359 deviances in mean annual temperature for each site in contrast to the historical mean annual

360 temperature in the home site for both varieties.

361

362 Summarizing results using local adaptation metrics

363 For the reciprocal part of the trial, we calculated local adaptation metrics from the mean

364 estimated combined predicted values obtained through the fixed effects Garden-model (see the

365 mathematical formulas below and Table S6). We did not include the out-of-range experimental

366 sites in order to specifically enable quantification of local adaptation patterns of the two varieties

367 within the distribution area of the variety. This gives an indication of the current situation of

368 local adaptation, while including the out-of-range gardens would confuse the interpretability of 
369 the metrics over time and space. There are three main approaches to make quantitative

370 comparisons of local adaptation from performance measures (Blanquart et al., 2013). The

371 sympatric-allopatric contrast (henceforth called $\triangle S A$ ) focuses on the difference between the

372 average performance of the genotypes in their home environment and non-home environment.

373 Thus, it describes how well the genotypes overall fit their home-environments. The home vs.

374 away approach $(H A)$ in turn describes the home environment quality for each tested genotype,

375 and is measured by the difference between the fitness of a genotype in its home environment and

376 the away environment. Finally, the local vs. foreign approach $(L F)$ describes the genotype quality

377 for each tested home environment, and is measured by the difference between the fitness of a

378 genotype in its home environment and the mean fitness of all other genotypes when exposed to

379 the same environment. These three conceptual approaches relate to different aspects of local

380 adaptation, all of which lie in the interest of our study: the overall habitat quality, the overall

381 quality of the variety, and how the two varieties fit the different environmental conditions.

382 Below, we provide a brief description of the metrics that we used, while a more thorough

383 definition can be found in the Supplementary Material Text S1 and in Blanquart et al. (2013).

384

385 We estimated the mean performance for an average sized plant of each variety in each

386 experimental garden over four years (based on the aster model predictions). We used these

387 estimates to calculate local adaptation metrics. Specifically, $\triangle S A$ for the subspecies as whole is

388 the difference between the mean performance $(p)$ of both varieties (northern, $\mathrm{N}$, southern $\mathrm{S}$ ) in

389 their home $(\mathrm{H})$ environments and that in the test (away, A) environment:

390

$$
\Delta S A=\frac{p_{N H}+p_{S H}}{2}-\frac{p_{N A}+p_{S A}}{2}
$$


392 The Home vs. Away metric $(H A)$ for each variety is the difference between the performance of

393 each variety in its home environment and that in its away environment.

394

395

396

397

398

399

400

401

402

403

404 405

406

407

408

409

410

411

\section{Results}

413 Realized weather conditions during the experimental years

414 The weather conditions during the experimental years differed between the experimental gardens

415 in accordance with what we expected when designing the experiment (Fig. 2, Fig. S4). However,

416 the observed temperatures were warmer than the historic means. In essence, this means that the 
417 experienced temperature conditions in Svanvik resembled the historic average temperatures in 418 Oulu (deviation of $0.146^{\circ} \mathrm{C}$ ), while the experienced temperatures in Oulu resembled, or were 419 even warmer than, the historic average temperatures in the out-of-range gardens in Rauma, 420 Helsinki, and Tartu (Fig. 2). The northern variety, however, did not experience conditions 421 corresponding to historical temperature in its home site in any of the experimental sites, as even 422 the coldest site, Svanvik, deviated from its historic mean annual temperature by $+1.146{ }^{\circ} \mathrm{C}$. The 423 variation in bioclimatic variables between gardens and years are shown in Fig. S5. Additional 424 variables describing the weather conditions during the historic period and experimental years are 425 provided in Figures S4 and S5.

426

427 Plant survival

428 Altogether, 110 out of $590(18.6 \%)$ plant individuals survived in the experiment by 2016. Low 429 survival is common in transplantation experiments (Dalrymple, Banks, Stewart, \& Pullin 2012). 430 However, there were large differences in survival between the varieties and the gardens in our 431 experiment. The survival across gardens was $8.8 \%(27 / 307)$ for the northern variety and $29.3 \%$ $432(83 / 283)$ for the southern variety. The survival varied between the gardens from $5.8 \%$ in Tartu $433(9 / 155)$ to $51 \%$ in Svanvik (52/102; Fig. 3, Table S3).

435 Individuals of the southern variety survived at a higher percentage every year and in each garden 436 (Fig. 3; Table S3), yet, the difference in survival between the varieties varied according to the 437 garden. Both varieties showed roughly the same trend, surviving worst in the out-of-range 438 gardens (Rauma, Helsinki, and Tartu) and best in the northernmost garden (Svanvik) (Fig. 3; 439 Table S3). 
$441 \quad$ Flowering and plant size

442 Mean values of our data on flower presence, flowering abundance and size $\left(\mathrm{cm}^{2}\right)$ are presented in

443 Fig. S6, both across all planted individuals and across all individuals that were alive in the focal

444 year. Among all the planted individuals, flowering was most frequent and abundant, and plants

445 grew biggest in Svanvik. The southern variety also grew well and flowered abundantly in

446 Helsinki. When considering only the surviving individuals, however, both varieties flowered

447 frequently and abundantly in Tartu and Rauma and the surviving individuals of the southern

448 variety grew big in all southern gardens. Yet, in many cases the number of surviving individuals

449 was very low, for example, only one individual of the northern variety was alive in Tartu in 2016

450 (Table S3), but it flowered.

451

452 Overall performance

453 Both the Garden and Temperature models revealed similar and significant differences between

454 the varieties in their overall performance (Table 1; Fig. 4). The Garden model indicated

455 increased performance of both varieties in gardens towards the north but revealed substantial

456 differences between the varieties (Fig. 4a; Table S6). Likewise, the Temperature model revealed

457 a significant negative effect of mean annual temperature on the performance on both varieties,

458 with a stronger negative effect on the northern variety (Fig. 4b; Table S7). Indeed, we found

459 significant interaction effects between variety vs. experimental garden (Fig. 4a; Table 1) and

460 annual temperature (Fig. 4b; Table 1). In addition, the original size at planting had a highly

461 significant effect on plant performance in both models (Table 1). The varieties are

462 morphologically different, including in size: the southern variety is generally bigger than the 
463 northern variety (Mäkinen \& Mäkinen 1964). As described in the methods, this was taken into

464 account by centering the variables describing original size around the mean of each variety,

465 wherefore the response in overall performance as a function of original size measures the relative 466 effect of size per variety.

467

468 Of the random effects, Plot explained a significant proportion of the residual variance (change in 469 deviance was 40 and 60 when Plot was omitted from the model for the Garden and Temperature 470 models, respectively) while Seed sampling site explained a marginal and non-significant 471 proportion of the residual variation (Table 1; Tables S4 and S5).

472

473 The aster models provide an overall performance estimate based on flower abundance per variety 474 in each garden, conditional on survival and presence of flowers. For the southern variety, these 475 estimates (Fig. 4., Table S6 and S7) were highest in Svanvik, followed by Helsinki (however 476 with overlapping standard deviations of estimates; Fig. 4 and Table 1). The overall performance 477 of the northern variety corroborated our hypothesis (Fig. 1b) by showing the highest performance 478 in its home-environment Svanvik, followed by Oulu, and performing worse in all three out-of479 range gardens (Tartu, Helsinki, and Rauma). An additional model on the deviances of 480 temperature from the historical mean instead indicated that the less deviance, the better both 481 varieties perform (Fig. S7). However, the southern variety still out-performed the northern 482 variety, indicating that other factors in addition to climate are important for explaining the 483 performance of these varieties.

484

485 Local adaptation metrics 
486 The local adaptation metrics based on the reciprocal part of the experiment (Tables S6 and S8) 487 suggested maladaptation to the current home environments of both varieties. For the southern 488 variety, the $H A$-value of -0.71 indicates that it experiences reduced habitat quality in its home 489 environment, as it thrives better away (in Svanvik) than at home (in Oulu). The $L F$ of 0.26, 490 however, indicates that the southern variety possesses superior quality in Oulu since it still does 491 better at home than the tested foreign northern variety does in Oulu. For the northern variety, the $492 H A$ of 0.22 indicates that it experiences superior habitat quality in its home environment 493 (Svanvik) compared to the tested away-environments (Oulu). Nevertheless, the $L F$ of -0.75 494 indicates that this variety is of reduced quality in its home environment, as the foreign (southern) variety performs better there. Mean $\triangle S A$ for the subspecies as a whole was -0.25 indicating an 496 overall negative fit of the environments for the subspecies.

498 Discussion

499 Our results reveal clear patterns of adaptation to macroclimatic conditions at the subspecies 500 level. In general, both varieties showed their best performance within the species' current range. 501 The southern variety showed higher overall performance in all experimental gardens, compared 502 to the northern variety. The overall survival and size as well as flowering frequency and 503 abundance tended to be higher for the southern variety. This is largely in line with the results 504 from a greenhouse experiment conducted by Mäkinen \& Mäkinen (1964). In that study, the 505 northern variety flowered only in cold night conditions $\left(12 \mathrm{~h} 21{ }^{\circ} \mathrm{C}+12 \mathrm{~h} 5{ }^{\circ} \mathrm{C}\right.$ versus $24 \mathrm{~h} 21$ $506{ }^{\circ} \mathrm{C}$ ), whereas the southern variety flowered only in continuously warm conditions but showed 507 increased vegetative growth in the cold night conditions. Similarly in our study, the northern 508 variety flowered most frequently in cooler conditions towards the north and rarely in the south. 
510 We did not find characteristic indications of local adaptation at the variety level, when looking at

511 the performance of the sampled populations per experimental garden. Individuals of both

512 varieties survived best, and flowered more frequently and abundantly, in the northernmost

513 garden Svanvik. This pattern is also evident from the local adaptation metrics, where the $L F$

514 metric indicated that the southern variety was superior in the home environment of the northern

515 one. Further, the overall performance proxy, the sympatric-allopatric contrast, indicated that the

516 varieties may have become maladapted to the conditions that prevail at present in their current

517 environments. This suggests that the conditions have already changed, compared to historical

518 conditions to which the populations were better adapted. In other words, the varieties are

519 suffering from a so-called adaptational lag (McGraw et al. 2015). When considering the weather

520 conditions during the experimental years, compared to the historic climatic conditions (Fig. 2 (b),

521 Fig. S4), a conclusion of local adaptation to historical temperature conditions indeed becomes

522 the most parsimonious explanation. This is revealed by the fact that the historical mean annual

523 temperature of the southern variety was most closely realized in Svanvik during the experimental

524 years, while the historical mean annual temperature for the northern variety was not realized in

525 any of the experimental gardens. In addition, the mean annual temperature in Oulu resembled

526 that of the three southern gardens' historical means, which was the climate change treatment that

527 we had envisioned. Thus, the conditions that we aimed to mimic through our experimental

528 design had in practise shifted locations one step further north, which we did not take into account

529 initially, when verbalising our hypotheses. Our findings are also supported by a species

530 distribution modelling study that tested the difference between modelling at the level of variety

531 and at the level of subspecies (Hällfors et al. 2016). According to the conclusions of that study, 
532 the southern population, if indeed locally adapted to the historical conditions in its current range,

533 should already by the 2030s find suitable conditions in the current distribution of the northern

534 variety, while the same conditions will no longer remain suitable for the northern variety.

535

536 Maladaptation is presumably increasing due to climate change, as the rapid change outpaces the

537 ability of species to adapt or migrate, and conditions reach beyond the extent of temperature

538 tolerance (Crespi, 2000; Kooyers et al., 2019). Our findings are in line with studies showing

539 signs of maladaptation to current climatic conditions in plant species (see Anderson \&

540 Wadgymar, 2020; Gellie et al., 2016; Kooyers et al., 2019; Wang, et al., 2019; Wilczek et al.,

541 2014). McGraw et al. (2015) found that the climatic optimum of their study species had shifted

542 by $140 \mathrm{~km}$. Our study reveals a displacement over a much longer extent: the distance between

543 the seed sampling sites of the southern variety and the Svanvik experimental sites is over 500

$544 \mathrm{~km}$.

545

546 Although maladaptation may be increasing because of climate change, it can also be caused by

547 underlying population genetic structures, such as genetic drift or founder effects (Crespi, 2000;

548 Leimu \& Fischer, 2008) related to the biogeographic history of the populations. The two

549 varieties of Siberian primrose probably became spatially separated during the end of the last

550 glacial period (Mäkinen \& Mäkinen, 1964), which first allowed colonization of emerging areas

551 and later fragmented the population through diminishing suitable habitat, as land masses re-

552 formed from underneath the receding ice shelves (see Kreivi et al., 2011). Indeed, genetic and

553 allelic diversity is known to be remarkably low in all populations of the Siberian primrose in

554 Fennoscandia (Kreivi et al., 2011). However, the consistent pattern of increased performance of 
555 both varieties from south to north suggests that maladaptation caused by recent change in climate

556 is a likely explanation for the results of this study. Maladaptation due to drift or other stochastic

557 processes would be geographically random, and a pattern consistent with a spatial gradient

558 would likely not appear. In addition, at least for the southern variety, this is not only a question

559 of relative maladaptation (for definition of terms, see Brady et al., 2019). According to threat

560 assessments, it also shows absolute maladaptation in the form of population decline (Hyvärinen

561 et al. 2019, results for this species available at

562 https://punainenkirja.laji.fi/en/results/MX.38659?checklist=MR.424).

563

564 Potential confounding effects and general limitations of transplantation experiments

565 While our results suggest a strong impact of climate on the Siberian primrose, they are not 566 conclusive. Large-scale translocation experiments are complex, and it is important to evaluate

567 potential methodological pitfalls. Transplantation experiments along the north-south axis

568 necessarily contain confounding effects, such as day length and other non-thermal environmental

569 conditions (Saikkonen et al., 2012; Björkman et al., 2016), which cannot be removed in a

570 transplantation study. Despite the rigorous measures to standardise treatments in all the gardens

571 (See Text S1), we had only one experimental garden at each latitude (albeit with three plots in

572 each garden). Therefore, random variation in care, pressure from weeds, and weather events may

573 have confounded the climatic signals. For example, some plots may have experienced short

574 periods of drought despite our regime of additional watering designed to mimic the natural

575 conditions experienced by this species of damp seashore meadows. The roughly three-year

576 observation period of our study may also not fully represent the prevailing climates in the

577 gardens, since inter-annual variation in weather may mask mean climatic differences, nor does 
578 such a short experiment necessarily reveal local adaptation (Bennington et al. 2012). The fact

579 that the site-specific deviance in mean annual temperature did not explain the relative poor

580 performance of the northern variety, indicates that other factors, like more nuanced differences in

581 climate, photoperiodic cues, or site-specific variation had a strong effect on performance. Long-

582 term studies would even out annual variations and allow the measurement of characteristics that

583 become available later in a plant's life cycle and population development (seed production and 584 germination, adaptation across generations, etc.).

585

586 In our study, plants that were larger at the time of planting showed higher overall performance.

587 Previous studies of reintroductions have shown that the best results (the highest numbers of

588 surviving plants) are gained by using seeds or mature plants (Dalrymple et al., 2012). However,

589 in an experimental study, we believe that using mature plants can be confounding since they may

590 be affected by the climatic conditions of the garden where they are propagated for the

591 experiment, thus possibly biasing the results through stronger priming effects (see below for a

592 discussion of the potential effect of Helsinki on the southern variety). Also, early stages in the

593 life cycle may be the ones most susceptible to climate change as they define the environments to

594 which post-germination life-stages of the individuals are exposed (Donohue et al., 2010), and

595 therefore they should not be omitted from a test setting. On the other hand, while running

596 experiments from seeds would have allowed us to evaluate performance through germination,

597 this might have risked the experiment in case of failure to germinate. In fact, even in the

598 relatively stable greenhouse conditions, the germination percentage of these varieties was

599 relatively low (27-69\%; depending on the sampling site; Lehtimäki 2016).

600 
601 The seeds of each variety were sampled in a single region within a c. $10 \mathrm{~km}$ radius (Fig. 1, Table

602 S1). Thus, from the data at hand, we cannot infer patterns across the complete ranges of the

603 varieties. Nevertheless, the genetic variation within each variety is relatively low (Kreivi et al.,

604 2011) and the varieties occur in distinct climatic environments (Hällfors et al. 2016), which

605 makes it plausible to assume that individuals across the range of each variety would respond

606 similarly to environmental conditions.

607

608 We did not control for, or try to remove, maternal carry-over effects, for instance through

609 growing a first generation in identical and controlled conditions and then utilizing the progeny

610 for the trials. However, the random effect of seed sampling site did not significantly increase the

611 explanatory power of residual variation. On the other hand, the lack of replication across the

612 distribution of the varieties inevitably lessens the potential for drawing strong conclusions about

613 the strength of local adaptation and potential effects of climate change for the subspecies as a

614 whole.

615

616 Another useful performance measures would have been seed production of the tested individuals

617 from the experimental locations and subsequent germination of the seeds. However, because of

618 limited resources and the possibility of hybridization between the two varieties, we restricted our

619 observations to the most readily observable performance measures of the planted populations. In

620 natural conditions each seed capsule may contain tens to hundreds of seed. Assuming that

621 pollination was successful (the species is pollinated by a variety of insects including small flies

622 which are present at all sites), flower number would be a relevant proxy for seed set. Although

623 germinability of seeds is a more conclusive indicator of reproductive capacity and population 
624 fitness, flowering is also an important indicator of the existence of a necessary life cycle stage

625 towards offspring. In addition, for this species, flowering has been shown to be an important

626 fitness-reflecting factor, as failure in flowering is connected to increased extinction risk of the

627 species (Björnström et al., 2011).

628

629 Why the southern variety thrived relatively well in Helsinki remains unclear. The raw proportion 630 of surviving individuals in Helsinki (31\%) was not substantially higher than in Oulu and Rauma

631 (24.5 and 23\%, respectively). However, the overall performance estimate, which describes

632 population-level flowering output, was substantially higher in Helsinki (4.1) than in the variety's

633 home environment in Oulu (1.69), and in Rauma (1.01). We suspect that this could have been

634 caused by the above-mentioned difference in general maintenance or weather conditions that we

635 were unable to capture through long-term means. Because the individuals were propagated

636 together in common conditions in Helsinki, the difference between these conditions and those of 637 the experimental garden, where the individuals ended up, could additionally explain the high

638 performance in Helsinki. If the individuals planted in Helsinki were primed to the Helsinki

639 conditions, this might explain the higher performance of them compared to the other southern

640 gardens and to Oulu. However, as this higher performance was not seen for the northern variety

641 (although the varieties may be differentially affected by priming) we suspect that the main cause 642 was stochastic effects.

643

644 The effect of climate change on the Siberian primrose

645 In this study, we have elucidated the role that plasticity towards varying temperature conditions

646 can play within the boundaries of local adaptation for the Siberian primrose and its two varieties. 
647 We conclude that, especially for the northern variety, the existing plasticity towards warmer

648 conditions is very limited. As the climate continues to change, migration northwards could

649 enable the varieties of this species to cope with increasing temperatures. However, because of its

650 poor dispersal ability, habitat specialisation further reducing chances of range expansion, and

651 limited temperature tolerance, the available options for this species are restricted to the

652 production of characteristics suitable for the new climatic conditions in situ through evolutionary

653 adaptation. Nevertheless, it remains unclear how big a role evolutionary adaptation will play

654 under climatic change in relation to temperature tolerance (Arnold et al., 2019; Charmantier \&

655 Gienapp, 2014; Gienapp et al., 2008; Nicotra et al., 2010). It is also not clear whether selection

656 can act to increase or decrease plasticity to allow larger variation among phenotypes, which

657 could then respond adaptively to a range of temperature conditions (Arnold et al., 2019).

658

659 Our raw data indicate that those individuals that did survive in the southernmost gardens tended 660 to be big and to flower frequently and abundantly (Fig. S6). Thus, the elimination of individuals

661 that are maladapted to the conditions in each experimental garden leaves a survivor population

662 for which the impact of climate is not as decisive. The adaptive performance of the remnant

663 plants in the out-of-range gardens highlights how individual features may be key determinants

664 for continued survival when a population goes through a bottleneck (Carson, 1990). Whether

665 such a small founding population of a genetically impoverished species could form a viable

666 population under rapidly changing conditions is, however, uncertain. Experiments on the

667 evolutionary potential in this species are needed to draw more solid conclusions on the potential

668 for the species to overcome the lag in adaptation that it is likely currently experiencing. 


\section{Conclusions}

671 Siberian primrose, a habitat specialist and poor disperser with small and fragmented populations

672 that harbour low genetic variability and a limited thermal tolerance, is an example of a species

673 likely to suffer from the lack of adaptive capacity under rapid climatic change. Proactive

674 conservation methods, such as assisted migration, may be needed in order to save this species.

675 Overall, our results cause concern about the viability of the Siberian primrose, especially the

676 northern variety, for which the detrimental effects of climate change may become evident within

677 a few decades. In addition, these findings remind us of the need to take the population level into

678 account when modelling the effect of climate change on species (Souther \& McGraw, 2011;

679 Hällfors et al., 2016).

680

681 The results of this study also highlight a critical point in testing for local adaptation and plasticity

682 under the rapidly changing climate. If populations are not able to track ongoing changes, only

683 experiments both within and outside the current range of the species (or variety) can provide

684 accurate information regarding local adaptation and plasticity towards historical, current, and

685 future conditions. Local adaptation to historical conditions, which currently may prevail only

686 polewards and even outside of the species range, must be considered a possible scenario (e.g.,

687 Anderson \& Wadgymar, 2020; Gellie et al., 2016; Kooyers et al., 2019; McGraw et al. 2015;

688 Wilczek et al., 2014), in which case the home environment no longer represents the "home

689 climate". The out-of range gardens that were included in this study (Rauma, Helsinki, and Tartu)

690 can inform us about likely trajectories for future maladaptation in case the species is not able to

691 adapt evolutionally and climate continues to shift temperature isoclines. Climate change thus

692 gives cause for re-examining traditional reciprocal and out-of-range common garden experiments 
693 (Anderson \& Wadgymar, 2020), and to plan experiments with climatic and weather data at hand.

694 Comparing responses to future, current, and historical conditions offers a powerful approach for

695 future studies (Anderson \& Wadgymar, 2020; Franks et al., 2007; Merilä \& Hendry, 2014;

696 McGraw et al. 2015; Thomann et al., 2015). Together with continued monitoring of population

697 abundances (Cotto et al., 2017), such studies can provide early warning signals for potential

698 feed-back effects on the ecosystem productivity (Schedlbauer et al. 2018; Curasi et al. 2019) and 699 species that may be close to tipping points and to going extinct.

700

701 Acknowledgements

702 We are grateful to the botanic gardens that provided staff and premises for conducting the trials:

703 University of Tartu, University of Helsinki, University of Turku teaching garden in Rauma,

704 University of Oulu, and NIBIO Svanhovd. We thank Pertti Pehkonen, Outi Pakkanen, and

705 Toomas Kangro for technical assistance in preparing the experiments. Terhi Ryttäri and Henry

706 Väre gave advice on the species and required soil properties. Ritva Hiltunen and Tuomas

707 Kauppila assisted in collection of seeds, Elina Vaara helped with permits for seed and plant

708 transfers, Hanna Finne with data management, and Bess Hardwick with acquiring weather data.

709 MHH was supported by the University of Helsinki Research Fund, LUOVA - Doctoral

710 Programme in Wildlife Biology Research and the Jane and Aatos Erkko Foundation through the

711 Research Centre for Ecological Change, University of Helsinki. The study was supported by the

712 Academy of Finland grant 126915 and Societas pro Fauna et Flora Fennica. The authors declare

713 no conflicts of interest.

714

715 References 
716 Anderson, J. T., \& Wadgymar, S. M. (2020). Climate change disrupts local adaptation and 717 favours upslope migration. Ecology Letters, 23(1), 181-192. doi: 10.1111/ele.13427

718 Arnold, P. A., Nicotra, A. B., \& Kruuk, L. E. B. (2019). Sparse evidence for selection on 719 phenotypic plasticity in response to temperature. Philosophical Transactions of the Royal 720 Society B: Biological Sciences, 374(1768), 20180185. doi: 10.1098/rstb.2018.0185

721

722

723

724

725

726

727

728

729

730

731

732

733

734

735

736

737

Atkins, K. E., \& Travis, J. M. J. (2010). Local adaptation and the evolution of species' ranges under climate change. Journal of Theoretical Biology, 266(3), 449-457. doi: 10.1016/j.jtbi.2010.07.014

Banta, J. A., Ehrenreich, I. M., Gerard, S., Chou, L., Wilczek, A., Schmitt, J., ... Purugganan, M. D. (2012). Climate envelope modelling reveals intraspecific relationships among flowering phenology, niche breadth and potential range size in Arabidopsis thaliana. Ecology Letters, 15(8), 769-777. doi: 10.1111/j.1461-0248.2012.01796.x

Bennington, C. C., N. Fetcher, M. C. Vavrek, G. R. Shaver, K. J. Cummings, and J. B. McGraw. (2012). Home site advantage in two long-lived arctic plant species: results from two 30year reciprocal transplant studies. Journal of Ecology 100: 841-851. doi: 10.1111/j.13652745.2012.01984.x

Björkman, A.D., Vellend, M., Frei, E.R., and Henry, G.H.R. (2016). Climate adaptation is not enough: warming does not facilitate success of southern tundra plant populations in the high Arctic. Glob. Chang. Biol. 23: 1540-1551. doi:10.1111/gcb.13417.

Björnström, T., Hyvärinen, M., Siikamäki, P., Strengell, H., Väre, H., \& Tuomi, J. (2011). Demographic variability and population viability of an endemic variety of the Siberian primrose. Annales Botanici Fennici, 48(2), 107-119. Retrieved from JSTOR. 
738 Blanquart, F., Kaltz, O., Nuismer, S. L., \& Gandon, S. (2013). A practical guide to measuring 739 local adaptation. Ecology Letters, 16(9), 1195-1205. doi: 10.1111/ele.12150

740 Brady, S.P., Bolnick, D.I., Barrett, R.D.H., Chapman, L., Crispo, E., Derry, A.M., Eckert, C.G.,

741

742

743

744

745

746

747

748

749

750

751

752

753

754

755

756

757

758

759

760

Fraser, D.J., Fussmann, G.F., Gonzalez, A., Guichard, F., Lamy, T., Lane, J., McAdam, A.G., Newman, A.E.M., Paccard, A., Robertson, B., Rolshausen, G., Schulte, P.M., Simons, A.M., Vellend, M., Hendry, A. (2019) Understanding Maladaptation by Uniting Ecological and Evolutionary Perspectives. The American Naturalist 194:4, 495-515

Carson, H. L. (1990). Increased genetic variance after a population bottleneck. Trends in Ecology \& Evolution, 5(7), 228-230. doi: 10.1016/0169-5347(90)90137-3

Ceballos, G., Ehrlich, P. R., Barnosky, A. D., García, A., Pringle, R. M., \& Palmer, T. M. (2015). Accelerated modern human-induced species losses: Entering the sixth mass extinction. Science Advances, 1(5), e1400253. doi: 10.1126/sciadv.1400253

Charmantier, A., \& Gienapp, P. (2014). Climate change and timing of avian breeding and migration: evolutionary versus plastic changes. Evolutionary Applications, 7(1), 15-28. doi: 10.1111/eva.12126

Chevin, L.-M., Lande, R., \& Mace, G. M. (2010). Adaptation, Plasticity, and Extinction in a Changing Environment: Towards a Predictive Theory. PLOS Biology, 8(4), e1000357. doi: 10.1371/journal.pbio.1000357

Cotto, O., Wessely, J., Georges, D., Klonner, G., Schmid, M., Dullinger, S., ... Guillaume, F. (2017). A dynamic eco-evolutionary model predicts slow response of alpine plants to climate warming. Nature Communications, 8(1), 15399. doi: 10.1038/ncomms15399

Crespi, B. J. (2000). The evolution of maladaptation. Heredity, 84(6), 623-629. doi: 10.1046/j.1365-2540.2000.00746.x 
761 Curasi, S.R., Parker, T. C., Rocha, A.V., Moody, M.L., J. Tang, and N. Fetcher. (2019).

762 Differential responses of ecotypes to climate in a ubiquitous arctic sedge: implications for 763 future ecosystem C cycling. New Phytologist 223: 180-192

764 Dalrymple, S.E., Banks, E., Stewart, G.B., \& Pullin, A.S. (2012) A Meta-Analysis of Threatened 765 Plant Reintroductions from Across the Globe. In: Machinski and Haskins (Eds.), Plant Reintroduction in a Changing Climate. Promises and Perils (pp. 31- 50). Island Press.

767

768

769

770

771

772

773

774

775

776

777

778

779

780

781

Dawson, I. K., Vinceti, B., Weber, J. C., Neufeldt, H., Russell, J., Lengkeek, A. G., ... Jamnadass, R. (2011). Climate change and tree genetic resource management: maintaining and enhancing the productivity and value of smallholder tropical agroforestry landscapes. A review. Agroforestry Systems, 81(1), 67-78. doi: $10.1007 / \mathrm{s} 10457-010-9302-2$

Díaz, S., Settele, J., Brondízio, E., Ngo, H. T., Guèze, M., Agard, J., ... Vilá, B. (2019). Summary for policymakers of the global assessment report on biodiversity and ecosystem services of the Intergovernmental Science-Policy Platform on Biodiversity and Ecosystem Services. 44.

Donohue, K., Rubio de Casas, R., Burghardt, L., Kovach, K., \& Willis, C. G. (2010). Germination, Postgermination Adaptation, and Species Ecological Ranges. Annual Review of Ecology, Evolution, and Systematics, 41(1), 293-319. doi: 10.1146/annurevecolsys-102209-144715

ENSCONET 2009: ENSCONET Seed Collecting Manual for Wild Species. Available at: http://ensconet.maich.gr/PDF/Collecting_protocol_English.pdf 
782 Fick, S. E., \& Hijmans, R. J. (2017). WorldClim 2: new 1-km spatial resolution climate surfaces

783 for global land areas. International Journal of Climatology, 37(12), 4302-4315. doi:

784 10.1002/joc.5086

785 Frankham, R., Ballou, J. D., Dudash, M. R., Eldridge, M. D. B., Fenster, C. B., Lacy, R. C., ...

786 Ryder, O. A. (2012). Implications of different species concepts for conserving

787 biodiversity. Biological Conservation, 153, 25-31. doi: 10.1016/j.biocon.2012.04.034

788

Franks, S. J., Sim, S., \& Weis, A. E. (2007). Rapid evolution of flowering time by an annual

789 plant in response to a climate fluctuation. Proceedings of the National Academy of

790 Sciences, 104(4), 1278-1282. doi: 10.1073/pnas.0608379104

791

792

793

794

795

796

797

798

799

800

801

802

803

Frenne De, P., Graae, B. J., Rodríguez-Sánchez, F., Kolb, A., Chabrerie, O., Decocq, G., ... Verheyen, K. (2013). Latitudinal gradients as natural laboratories to infer species' responses to temperature. Journal of Ecology, 101(3), 784-795. doi: 10.1111/13652745.12074

Gao, S., Mo, L., Zhang, L., Zhang, J., Wu, J., Wang, J., ... Gao, Y. (2018). Phenotypic plasticity vs. local adaptation in quantitative traits differences of Stipa grandis in semi-arid steppe, China. Scientific Reports, 8(1), 3148. doi: 10.1038/s41598-018-21557-w

GBIF (2013). Global Biodiversity Information Facility Data Portal.

Gellie, N. J. C., Breed, M. F., Thurgate, N., Kennedy, S. A., \& Lowe, A. J. (2016). Local maladaptation in a foundation tree species: Implications for restoration. Biological Conservation, 203, 226-232. doi: 10.1016/j.biocon.2016.08.036

Geyer, C. J., Wagenius, S., \& Shaw, R. G. (2007). Aster models for life history analysis. Biometrika, 94(2), 415-426. doi: 10.1093/biomet/asm030 
804 Geyer, Charles J., Ridley, C. E., Latta, R. G., Etterson, J. R., \& Shaw, R. G. (2010). Aster

805 Models with Random Effects via Penalized Likelihood [Technical Report]. Retrieved

806 from University of Minnesota website: http://conservancy.umn.edu/handle/11299/199694

807 Geyer, Charles J., Ridley, C. E., Latta, R. G., Etterson, J. R., \& Shaw, R. G. (2013). Local

808 adaptation and genetic effects on fitness: calculations for exponential family models with 809 random effects. The Annals of Applied Statistics, 7(3), 1778-1795.

810 Geyer, C.J., (2017). R package aster2 (Aster Models), version 0.3. https://cran.r-

$811 \quad$ project.org/package=aster2.

812 Geyer, C.J., (2019): The Aster Package Tutorial. Available at: https://cran.r-

813 project.org/web/packages/aster/vignettes/tutor.pdf

814

815 Gienapp, P., Teplitsky, C., Alho, J. S., Mills, J. A., \& Merilä, J. (2008). Climate change and 816 evolution: disentangling environmental and genetic responses. Molecular Ecology, 17(1),

817 167-178. doi: 10.1111/j.1365-294X.2007.03413.x

818 Greiser, C., Hylander, K., Meineri, E., Luoto, M., \& Ehrlén, J. (2020). Climate limitation at the 819 cold edge: contrasting perspectives from species distribution modelling and a transplant

820 experiment. Ecography, n/a(n/a). doi: 10.1111/ecog.04490

821

822

823

824

825

826
Hällfors, M. H., Vaara, E. M., Hyvärinen, M., Oksanen, M., Schulman, L. E., Siipi, H., \& Lehvävirta, S. (2014). Coming to Terms with the Concept of Moving Species Threatened by Climate Change - A Systematic Review of the Terminology and Definitions. PLOS ONE, 9(7), e102979. doi: 10.1371/journal.pone.0102979

Hällfors, M. H., Liao, J., Dzurisin, J., Grundel, R., Hyvärinen, M., Towle, K., Wu., G., Hellmann, J. J. (2016). Addressing potential local adaptation in species distribution 
827

828

829

830

831

832

833

834

835

836

837

838

839

840

841

842

843

844

845

846

847

848

849

models: implications for conservation under climate change. Ecological Applications, 26(4), 1154-1169. doi: 10.1890/15-0926

Hargreaves, A. L., Samis, K. E., \& Eckert, C. G. (2014). Are Species’ Range Limits Simply Niche Limits Writ Large? A Review of Transplant Experiments beyond the Range. The American Naturalist, 183(2), 157-173. doi: 10.1086/674525

Hill, J. K., Griffiths, H. M., \& Thomas, C. D. (2011). Climate Change and Evolutionary Adaptations at Species' Range Margins. Annual Review of Entomology, 56(1), 143-159. doi: 10.1146/annurev-ento-120709-144746

Hultén, E., \& Fries, M. (1986). Atlas of North European vascular plants: north of the Tropic of Cancer, vol. 1-3. Königstein, Koeltz.

Hijmans, R.J. (2019). raster: Geographic Data Analysis and Modeling. R package version 2.8-19. https://CRAN.R-project.org/package=raster

Hijmans, R.J., Phillips, S., Leathwick, J. \& Jane Elith, J. (2017). dismo: Species

Distribution Modeling. R package version 1.1-4. https:/CRAN.R-project.org/package=dismo Hultén E., and Fries M. (1986): Atlas of North European vascular plants: north of the Tropic of Cancer, vol. 1-3. Königstein, Koeltz.

Hyvärinen, E., Juslén, A., Kemppainen, E., Uddström, A. \& Liukko, U.-M. (eds.) (2019): The 2019 Red List of Finnish Species. (Ministry of the Environment \& Finnish Environment Institute, 2019).

IPCC, 2019: Summary for Policymakers. In: Climate Change and Land: an IPCC special report on climate change, desertification, land degradation, sustainable land management, food security, and greenhouse gas fluxes in terrestrial ecosystems [P.R. Shukla, J. Skea, E. Calvo Buendia, V. Masson-Delmotte, H.- O. Pörtner, D. C. Roberts, P. Zhai, R. Slade, S. 
850

851

852

853

854

855

856

857

858

859

860

861

862

863

864

865

866

867

868

869

870

871

872

Connors, R. van Diemen, M. Ferrat, E. Haughey, S. Luz, S. Neogi, M. Pathak, J. Petzold, J. Portugal Pereira, P. Vyas, E. Huntley, K. Kissick, M. Belkacemi, J. Malley, (eds.)].

Joint Research Centre 2014: Gridded Agro-Meteorological Data in Europe. URI: http://data.europa.eu/88u/dataset/jrc-marsop4-7-weather_obs_grid_2015

Kawecki, T. J., \& Ebert, D. (2004). Conceptual issues in local adaptation. Ecology Letters, 7(12), 1225-1241. doi: 10.1111/j.1461-0248.2004.00684.x

Kooyers, N. J., Colicchio, J. M., Greenlee, A. B., Patterson, E., Handloser, N. T., \& Blackman, B. K. (2019). Lagging Adaptation to Climate Supersedes Local Adaptation to Herbivory in an Annual Monkeyflower. The American Naturalist, 194(4), 541-557. doi: $10.1086 / 702312$

Kreivi, M., Aspi, J., \& Leskinen, E. (2011). Regional and local spatial genetic structure of Siberian primrose populations in Northern Europe. Conservation Genetics, 12(6), 15511563. doi: $10.1007 / \mathrm{s} 10592-011-0252-7$

Kreivi, M., Huttunen, S., \& Aspi, J. (2006). Isolation and characterization of polymorphic microsatellite markers from Primula nutans (Primulaceae). Molecular Ecology Notes, 6(2), 334-336. doi: 10.1111/j.1471-8286.2005.01222.x

Kreyling, J., Buhk, C., Backhaus, S., Hallinger, M., Huber, G., Huber, L., ... Beierkuhnlein, C. (2014). Local adaptations to frost in marginal and central populations of the dominant forest tree Fagus sylvatica L. as affected by temperature and extreme drought in common garden experiments. Ecology and Evolution, 4(5), 594-605. doi: 10.1002/ece3.971

Lampinen, R., Lahti, T., Heikkinen, M. 2012. Kasviatlas 2011. -- Helsingin Yliopisto, Luonnontieteellinen keskusmuseo, Helsinki. Distribution maps available at: http://www.luomus.fi/kasviatlas. 
873 Lehtimäki, I. (2016). Uhanalaisen ruijanesikon suojelu. Etäsuojelun ja avustetun leviämisen

874

875

876

877

878

879

880

881

882

883

884

885

886

887

888

889

890

891

892

893

894 näkökulma. Master's thesis [In Finnish]. Department of Biosciences, University of Helsinki.

Leimu, R., \& Fischer, M. (2008). A Meta-Analysis of Local Adaptation in Plants. PLoS ONE, 3(12), e4010. doi: 10.1371/journal.pone.0004010

Lenoir, J., \& Svenning, J.-C. (2015). Climate-related range shifts - a global multidimensional synthesis and new research directions. Ecography, 38(1), 15-28. doi: 10.1111/ecog.00967

Mäkinen, L., \& Mäkinen, Y. (1964). The distribution, ecology, morphology and taxonomy of Primula nutans Georgi ssp. finmarchica (Jacq.) Löve \& Löve. Annales Botanici Fennici, 1(4), 273-291. Retrieved from JSTOR.

McGraw, J. B., J. B. Turner, S. Souther, C. C. Bennington, M. C. Vavrek, G. R.Shaver, and N. Fetcher. (2015). Northward displacement of optimal climate conditions for ecotypes of Eriophorum vaginatum L. across a latitudinal gradient in Alaska. Global Change Biology 21: 3827-3835. doi: 10.1111/gcb.12991

Merilä, J. (2012). Evolution in response to climate change: In pursuit of the missing evidence. BioEssays, 34(9), 811-818. doi: 10.1002/bies.201200054

Merilä, J., \& Hendry, A. P. (2014). Climate change, adaptation, and phenotypic plasticity: the problem and the evidence. Evolutionary Applications, 7(1), 1-14. doi: 10.1111/eva.12137

Nicotra, A. B., Atkin, O. K., Bonser, S. P., Davidson, A. M., Finnegan, E. J., Mathesius, U., ... van Kleunen, M. (2010). Plant phenotypic plasticity in a changing climate. Trends in Plant Science, 15(12), 684-692. doi: 10.1016/j.tplants.2010.09.008 
895 Parmesan, C., \& Yohe, G. (2003). A globally coherent fingerprint of climate change impacts $896 \quad$ across natural systems. Nature, 421(6918), 37-42. doi: 10.1038/nature01286

897 Pelini, S. L., Diamond, S. E., MacLean, H., Ellison, A. M., Gotelli, N. J., Sanders, N. J., \& Dunn, 898 R. R. (2012). Common garden experiments reveal uncommon responses across 899

900 temperatures, locations, and species of ants. Ecology and Evolution, 2(12), 3009-3015.

901

902

903

904

905

906

907

908

909

910

911

912

913

914

915

916

917 doi: 10.1002/ece3.407

Pöyry, J., Luoto, M., Heikkinen, R. K., Kuussaari, M., \& Saarinen, K. (2009). Species traits explain recent range shifts of Finnish butterflies. Global Change Biology, 15(3), 732743. doi: $10.1111 / \mathrm{j} .1365-2486.2008 .01789 . x$

R Core Team 2019: R: A language and environment for statistical computing. R Foundation for Statistical Computing, Vienna, Austria. $<$ http://www.R-project.org/>.

Saikkonen, K., Taulavuori, K., Hyvönen, T., Gundel, P. E., Hamilton, C. E., Vänninen, I., ... Helander, M. (2012). Climate change-driven species' range shifts filtered by photoperiodism. Nature Climate Change, 2(4), 239-242. doi: 10.1038/nclimate1430

Schedlbauer, J. L., N. Fetcher, K. Hood, M. L. Moody, and J. Tang. (2018). Effect of growth temperature on photosynthetic capacity and respiration in three ecotypes of Eriophorum vaginatum. Ecology and Evolution 8: 3711-3725 doi: 10.1002/ece3.3939

Settele, J., Scholes, R., Betts, R., Bunn, S., Leadley, P., Nepstadt, D., \& Taboada, M. A. (2014). Terrestrial and inland water systems. In: Cambridge, United Kingdom and New York, NY, USA, pp. 271-359.

Shaw, R. G., Geyer, C. J., Wagenius, S., Hangelbroek, H. H., Etterson, J. R., Taylor, A. E. P. D., \& DeAngelis, E. D. L. (2008). Unifying Life-History Analyses for Inference of Fitness and Population Growth. The American Naturalist, 172(1), E35-E47. doi: 10.1086/588063 
918 Silvertown, J., \& Charlesworth, D. (2001). Introduction to Plant Population Biology. 4th edition. 919 Blackwell Science.

920 Souther, S., and McGraw, J.B. (2011). Evidence of Local Adaptation in the Demographic

921 Response of American Ginseng to Interannual Temperature Variation. Conserv. Biol. 25:

922 922-931. doi:10.1111/j.1523-1739.2011.01695.x.

923 Thiers, B. (2016) Index Herbariorum: A Global Directory of Public Herbaria and Associated 924 Staff. New York Botanical Garden’s Virtual Herbarium.

925 http://sweetgum.nybg.org/science/ih/

926

927

928

929

930

931

932

933

934

935

936

937

938

939

940

Thomann, M., Imbert, E., Engstrand, R. C., \& Cheptou, P.-O. (2015). Contemporary evolution of plant reproductive strategies under global change is revealed by stored seeds. Journal of Evolutionary Biology, 28(4), 766-778. doi: 10.1111/jeb.12603

Ulvinen, T. (1997). Rujanesikko. In: Uhanalaiset kasvimme. Ryttäri T. and Kettunen T. (eds.). [In Finnish]. Suomen ympäristökeskus, Helsinki.

Urban, M. C. (2015). Accelerating extinction risk from climate change. Science, 348(6234), 571-573. doi: 10.1126/science.aaa4984

Valladares, F., Matesanz, S., Guilhaumon, F., Araújo, M. B., Balaguer, L., Benito-Garzón, M., ... Zavala, M. A. (2014). The effects of phenotypic plasticity and local adaptation on forecasts of species range shifts under climate change. Ecology Letters, 17(11), 13511364. doi: $10.1111 /$ ele. 12348

Wang, Y., Pedersen, J. L. M., Macdonald, S. E., Nielsen, S. E., \& Zhang, J. (2019). Experimental test of assisted migration for conservation of locally range-restricted plants in Alberta, Canada. Global Ecology and Conservation, 17, e00572. doi: 10.1016/j.gecco.2019.e00572 
941 Wilczek, A. M., Cooper, M. D., Korves, T. M., \& Schmitt, J. (2014). Lagging adaptation to 942 warming climate in Arabidopsis thaliana. Proceedings of the National Academy of 943 Sciences, 111(22), 7906-7913. doi: 10.1073/pnas.1406314111

944 Yin, J., Zhou, M., Lin, Z., Li, Q.Q. \&Zhang, Y.-Y. (2019), Transgenerational effects benefit 945 offspring across diverse environments: a meta-analysis in plants and animals. Ecology $946 \quad$ Letters, 22: 1976-1986. doi:10.1111/ele.13373

947 Zenni, R. D., Bailey, J. K., \& Simberloff, D. (2014). Rapid evolution and range expansion of an 948 invasive plant are driven by provenance -environment interactions. Ecology Letters, 949 17(6), 727-735. doi: 10.1111/ele.12278 


\section{Figure 1}

Geographical distribution of seed sampling sites and experimental gardens (a), and hypotheses of plant performance in experimental gardens

Geographical distribution of seed sampling sites and experimental gardens (a), and hypotheses of plant performance in experimental gardens (b-e). Panel (a) shows the geographical distribution of seed sampling sites and experimental gardens with occurrences of Primula nutans ssp. finmarchica marked by dark grey points: Var. finmarchica occurs by the Arctic Sea in N-Norway and var. jokelae by the Bothnian bay in Finland and Sweden and the White Sea in Russia. Red = seed sampling sites of the southern variety (var. jokelae) in Finland; Blue= seed sampling sites of the northern variety (var. finmarchica) in Norway. Occurrence points are available in the supplementary data published in Dryad (https://doi.org/10.5061/dryad.3n5tb2rfk).The source for occurrence points are: Global Biodiversity Information Facility (GBIF 2013); Kastikka (Finnish plant distribution database; Lampinen, Lahti, \& Heikkinen 2012); records from the of Finnish Environment Institute; occurrences in Russia based on information from herbarium specimens (from collections in the herbarium of the Finnish Museum of Natural History [H sensu Thiers 2016] and the herbarium of the University of Turku [TUR sensu Thiers 2016] and manually included occurrence points based on visually inspecting the distribution map by Hultén and Fries [1986]). Panels (b-e) show hypothesized overall performance of the tested varieties in all experimental gardens following opposing underlying scenarios of (b) local relative adaptation (sensu Brady et al. 2019) at the varietal and subspecies level, (c) relative adaptation of the subspecies to its current environment vs. areas outside it, (d) tolerance (through plasticity) towards all tested conditions (including those not currently present within the occurrence area of the subspecies), and (e) relative maladaptation caused by climate change (see text for hypotheses). Dashed area demarks within-range gardens, i.e. the reciprocal part of the 
experiment. Red $=$ southern variety; blue $=$ northern variety

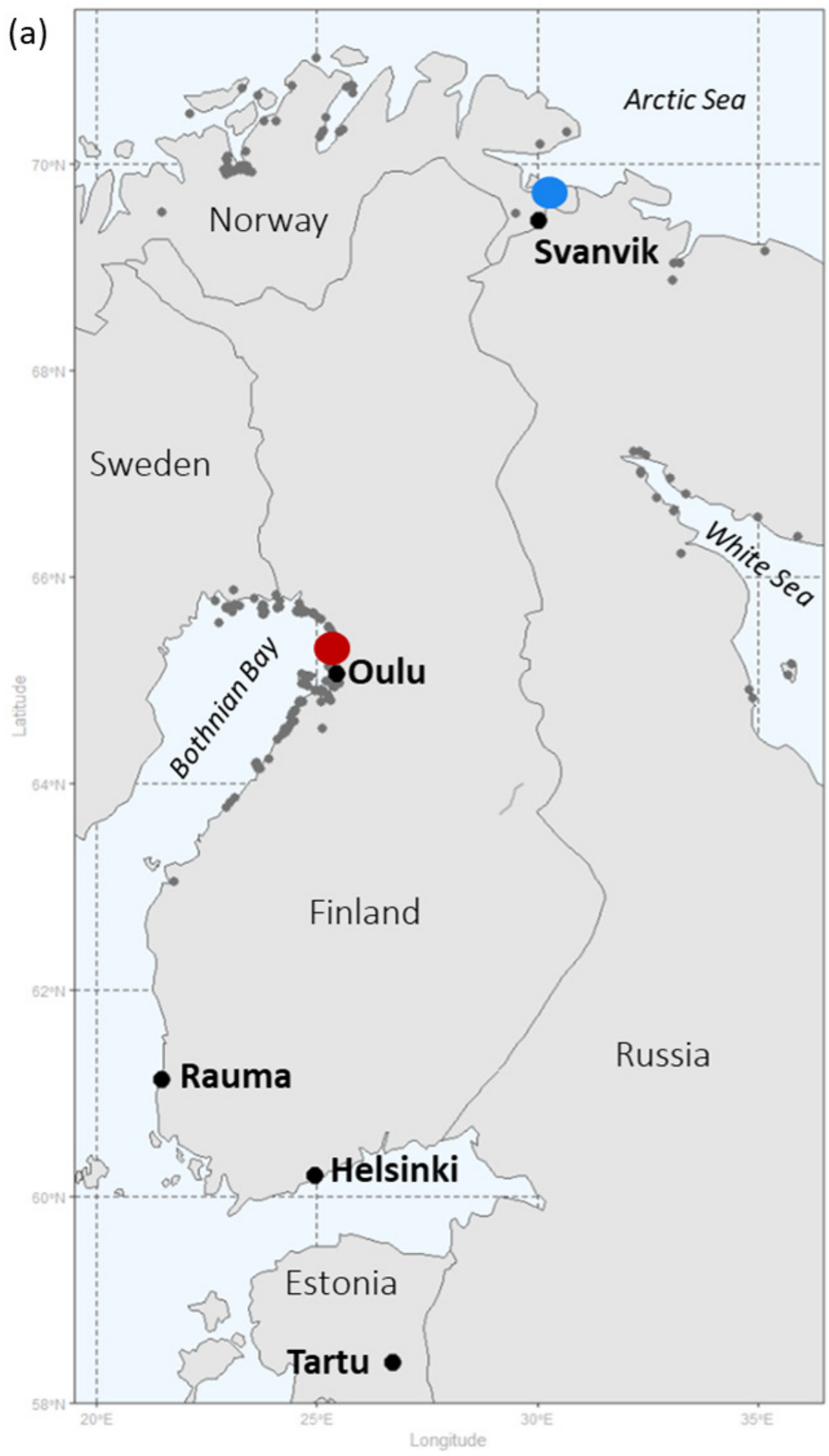

(b) Local adaptation of varieties

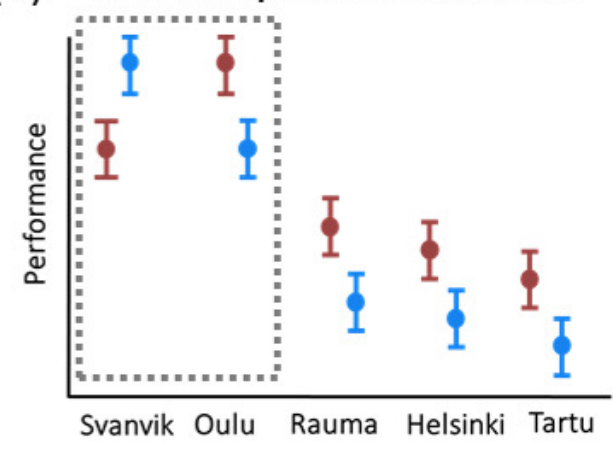

(c) Local adaptation of subspecies

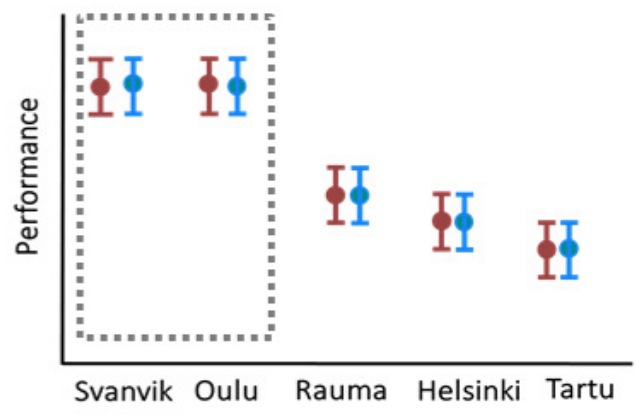

(d)

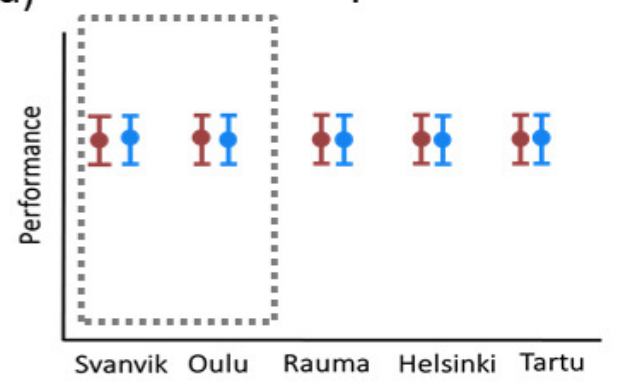

(e)

Maladaptation

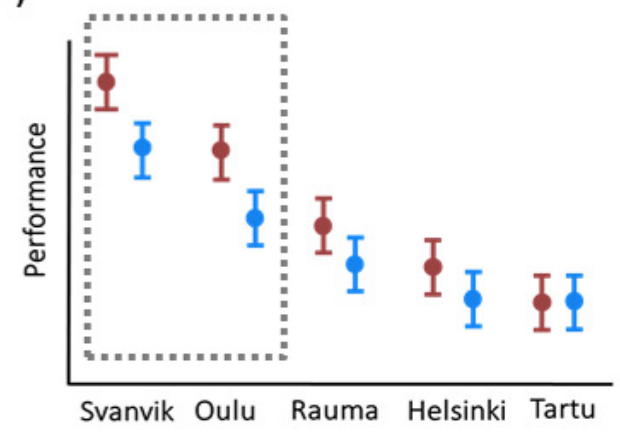




\section{Figure 2}

Mean annual temperature of seed sampling sites and experimental gardens.

Mean annual temperature of seed sampling sites and experimental gardens. Black points show historic mean temperatures (1970-2000; 10 minutes resolution; (Fick \& Hijmans, 2017) and gray points show the future projections of mean temperatures (CMIP5 for 2050, 10 minutes resolution, HADGEM2-ES model; (Fick \& Hijmans, 2017) for each experimental gardens and seed sampling sites (Northern= seed sampling sites of the northern variety; Southern = seed sampling sites of the southern variety). For experimental gardens, open circles show mean temperature during the experimental years 2013-2016. The experimental gardens and seed sampling sites within the species range are outlined by a dashed gray box, whereas the blue box indicates the sites within the range of the northern variety and the red box the sites within the range of the southern variety. Corresponding figures for precipitation sum and other climatic variables in Fig. S4. The future temperatures in Oulu approach the historic ones in Tartu, Helsinki and Rauma, and the future temperatures in Svanvik approach the historic ones in Oulu. During the experiment, mean temperatures were higher than the historic means. The conditions in Svanvik corresponded with historical means in Oulu. Those in Oulu approached the historic means in the southern gardens. 


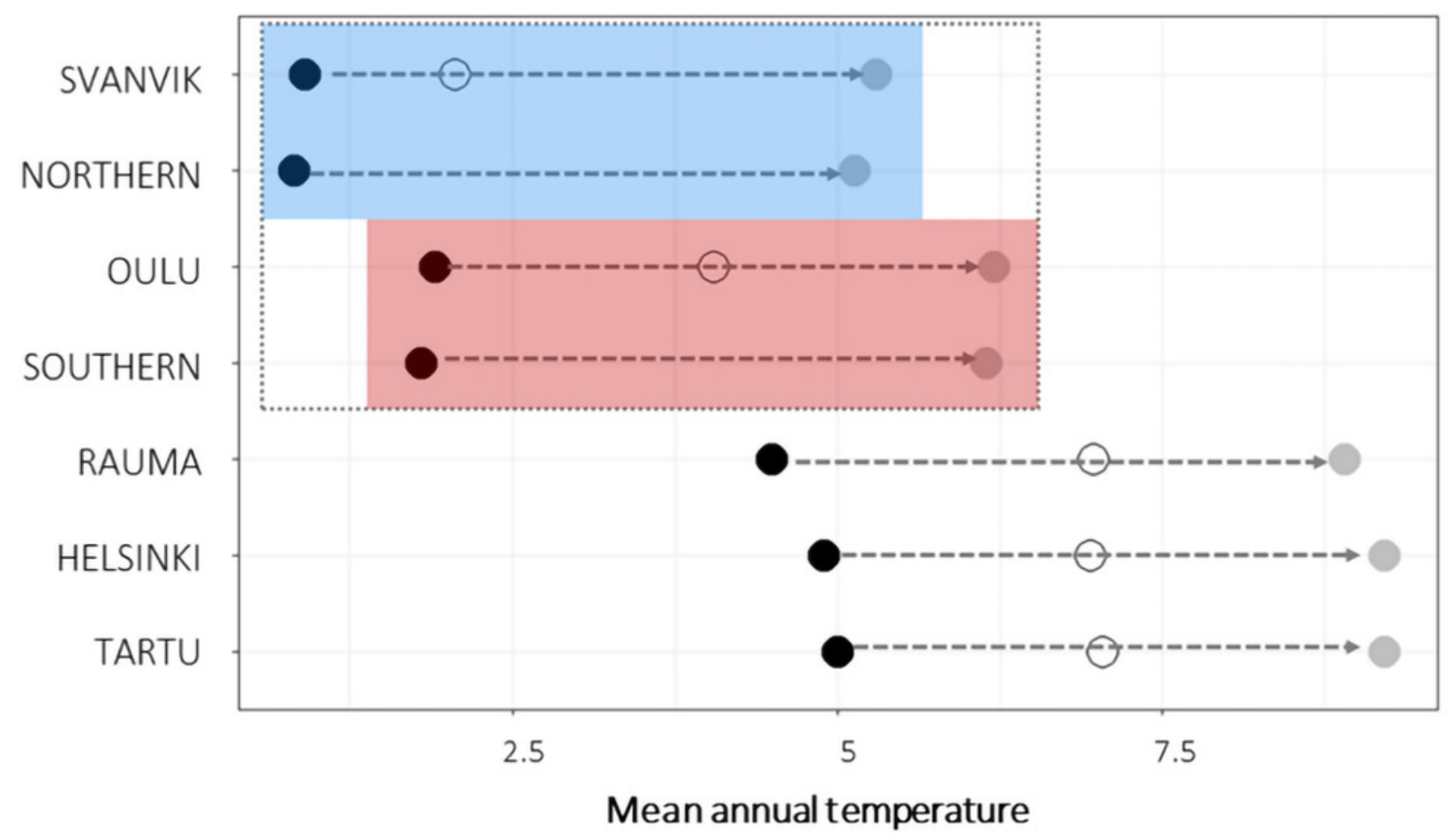




\section{Figure 3}

Mean survival per variety across gardens and years.

Mean survival per variety across gardens and years. The total number of individuals planted in 2013 appear at the top of the plot (both original plants and additional plants due to high die-off in the first summer). Red points = southern variety; blue points = northern variety. The size of the point indicates year: big point $=2014$; medium point $=2015$; small point $=$ 2016. Please refer to Table $\mathrm{S} 3$ for the exact numbers of individuals per year and garden, and percentage decrease over year. 


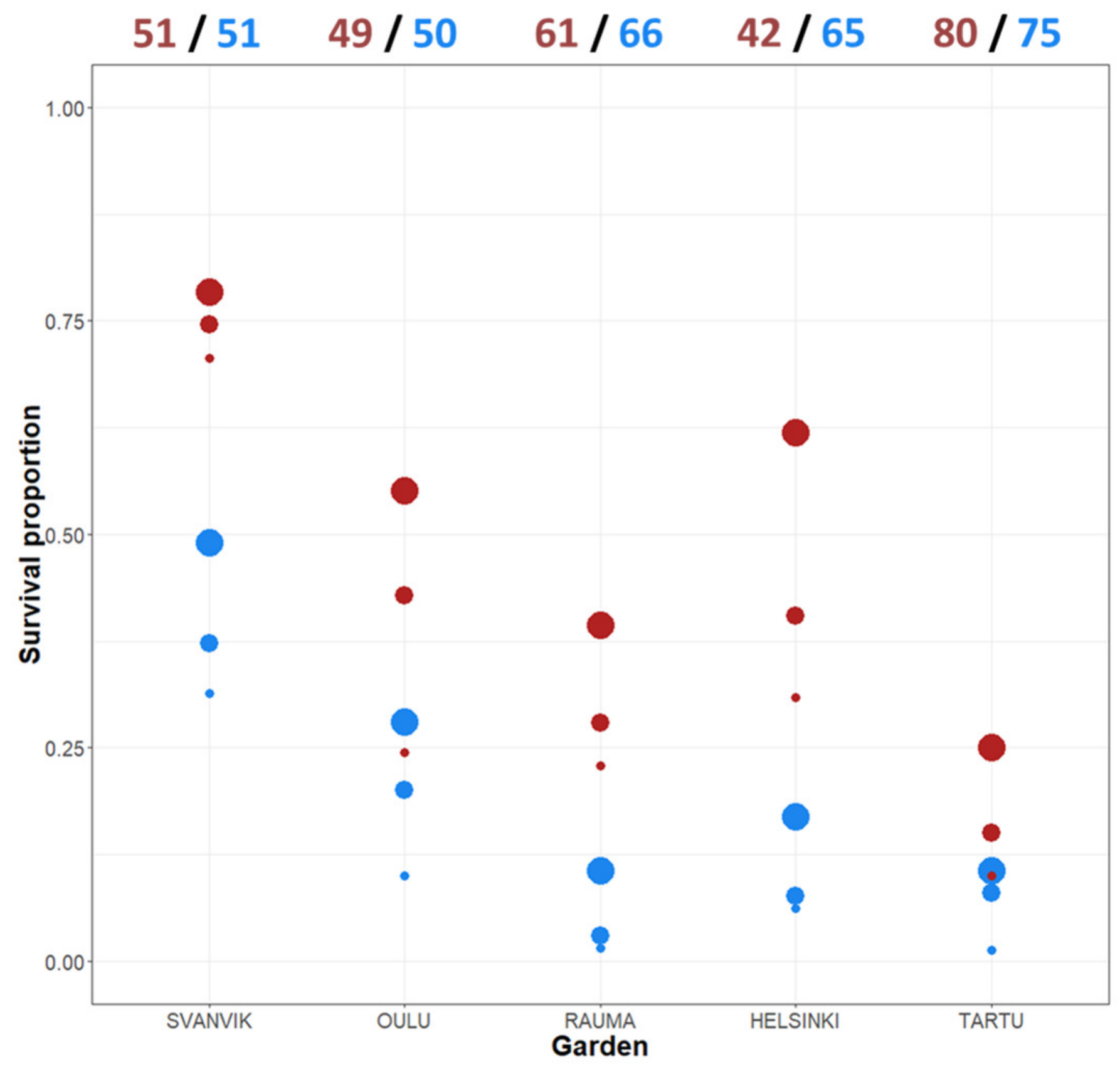




\section{Figure 4}

Predicted overall performance of the two varieties across experimental gardens, and mean annual temperature over the experimental period 2013-2016.

Predicted overall performance of the two varieties across (a) experimental gardens, and (b) mean annual temperature over the experimental period 2013-2016. Error bars represent $95 \%$ confidence intervals. Predictions are made for plants of average original size and based on the fixed effects aster model (i.e., not including Plot and Seed sampling site as random effects). Red= southern variety; blue= northern variety.
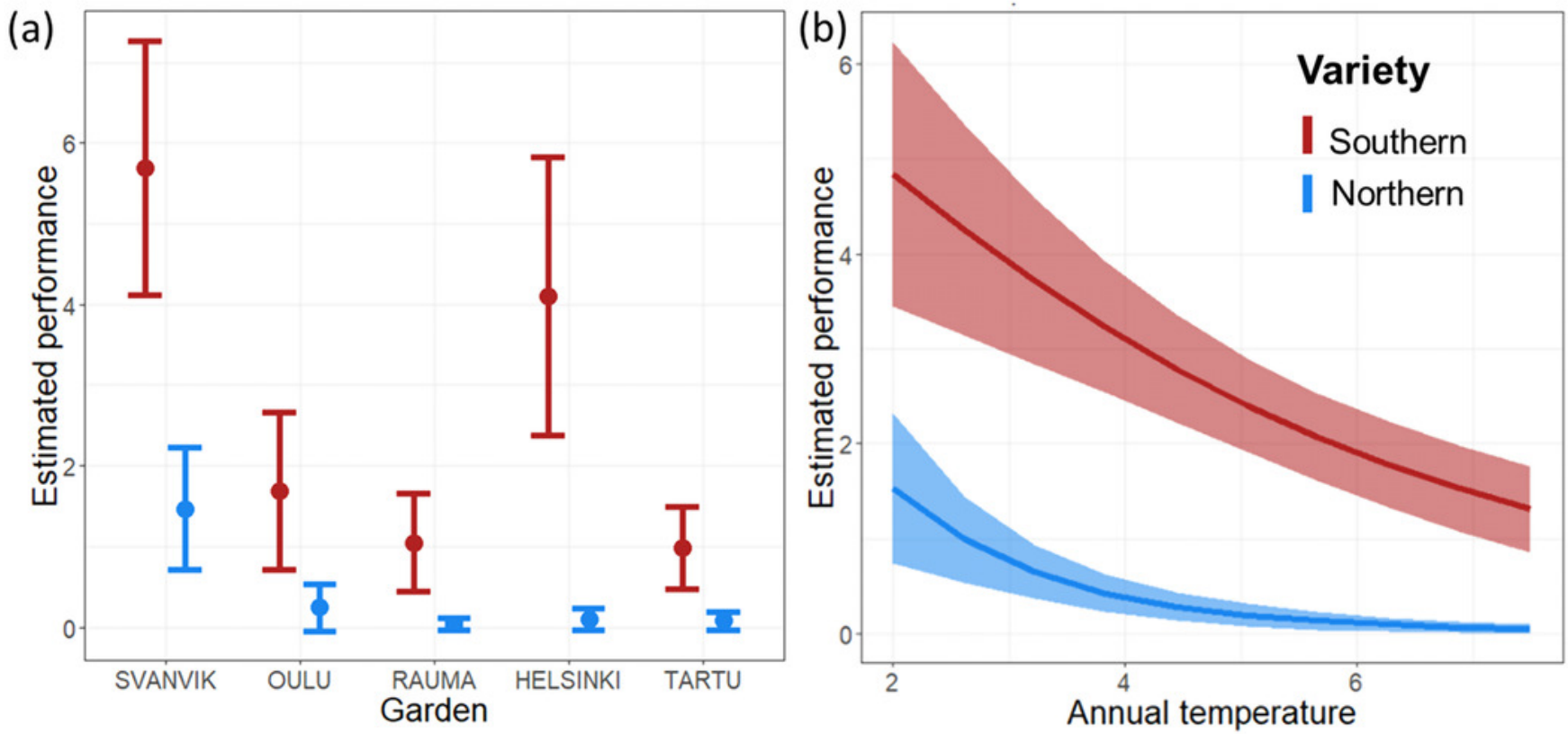


\section{Table $\mathbf{1}$ (on next page)}

Change in deviance when a single variable was omitted from the full random effects models.

Change in deviance when a single variable was omitted from the full random effects models. Summary from comparing aster models testing the fixed effects of experimental garden (lefthand side of table) or annual temperature (right hand side of table), variety and original size on plant performances, as well as Plot and Seed sampling site as random effects. Statistical significance of predictor variables was assessed using likelihood ratio tests, that is, a model where one variable was omitted was compared to the full model using anova. 


\begin{tabular}{|lll|c|rrr|}
\hline \multicolumn{3}{|c|}{ Garden-model } & \multicolumn{3}{c|}{ Annual temperature -model } \\
\hline p-value & df & $\begin{array}{l}\text { Change in } \\
\text { deviance }\end{array}$ & Change in & \\
deviance & df & $p$-value \\
\hline$<0.001$ & 1 & 62.4 & Variable & 60.2 & 1 & $<0.001$ \\
$<0.05$ & 4 & 11 & Original size & 8.8 & 1 & $<0.01$ \\
$<0.01$ & 5 & 20 & Variety:Garden/Ann.Temp. & 17.2 & 2 & $<0.001$ \\
$<0.05$ & 8 & 19.6 & Garden/Ann. Temp. (+ Variety:Garden/Ann. Temp.) & 14.2 & 2 & $<0.001$ \\
$<0.001$ & 0 & 46 & Plot & 60 & 0 & $<0.001$ \\
0.09 & 0 & 1.8 & Seed sampling site & 2.2 & 0 & 0.07 \\
\hline
\end{tabular}

1 